\title{
Feeling Visuality. Ideas of the Congenitally Blind People on the Sense of Sight and the Ability to See
}

$\mathrm{T}$ he aim of this article is to present the way congenitally blind ${ }^{1}$ individuals understand and imagine the functioning of sight and its general value. Due to the restricted scope of the article, I will limit my focus to the ideas and associations regarding the phenomenon of sight itself, omitting threads related to non-verbal communication or appearance, which were described by other researchers (Friedman 2012; Hammer 2012; Magnusson, Karlsson 2008). However, before I move to sharing individual stories and the observations collected during the fieldwork, I will briefly discuss the category of visual culture, values and meanings attributed to visual cognition, as well as selected theories on blindness that significantly affect the worldview of the blind people I encountered. One of the outcomes of the ethnographic research on the lives of blind individuals that I conducted in 2011-2017 is that it is the norms and ways of acting and perception established by the "sighted" that constitute a basic reference point for study participants. For this reason, this article combines general notions about sight and blindness with the specific experiences and imaginations of blind individuals, rooted in social norms and cultural patterns of perception characteristic of the "sighted world". In this sense, the perspective I have adopted is an attempt

1 In this research, I use the term "blind person" to refer to someone who, due to a significant or complete loss of sight, has to move outside his or her home with the aid of a white stick, guide dog or assistant. At the same time, I adopt the term "congenitally blind" to refer to people who are unable to see since birth or lost this ability in the first two years of life, and therefore have no visual memory and imagination, which in this context clearly distinguishes their experiences from the perspective of those blind individuals who lost sight in their youth or as adults (see Hull 2001). 
to combine the phenomenology of blindness, which focuses on the specificity of the experiences shared by the blind, and hermeneutics or dialectics of (lack of) sight, which illustrates the dependence of study participants on common social norms and connections in the field of visuality.

\section{Fieldwork Among Blind People: Methodological Issues}

The empirical base of my knowledge is ethnographic research on the practices and strategies of blind individuals that I conducted in 2011-2017. The study participants were 20 people aged 18-45, all congenitally blind, residing in various places across Poland (including Warsaw, Lodz, Szczecin and Cracow). The foundation of that research were various types of meetings and interviews, including joint participation in possibly various situations (travel, walks, visits to offices, taking part in cultural events, parties, etc.). In addition, I also became to know dozens of other blind and visually impaired people, thanks to whom I gained additional knowledge about the social and cultural conditions that dictate the way of life for the described group. I carried out a total of 110 interviews registered using a digital voice recorder and I held about 450 other types of meetings (including multi-day trips or visits at the homes of individual participants).

When conducting the research in question, I was trying to be open about the methods used, as well as to maintain an open attitude both towards my interlocutors and the situations encountered in the field. An important result of these efforts is the implementation - and at the same time a practical revision of the postulates of collaborative ethnography presented by Anna Wyka (1993) and Luke Eric Lassiter (2005). Proponents of this approach encourage taking into account the participants' voice at every stage of the research - from formulating the initial hypotheses and research questions, through presenting partial results, to reading and evaluating the final research report - as well as including it in the creation of academic or popular science articles (Wyka 1993; Lassiter 2005). How this collaboration and engagement may work is illustrated in the written comments coming from the interlocutors referring to the content of this article and placed at its end.

The analysis of the collected empirical material has not been performed in line with a specific, top-down interpretive framework. A systematic ordering and exploring of empirical data, based on strictly defined procedures and aimed at generating a certain theory - as is the case with grounded theory methodology (Konecki 2000: 26) - was also not the assumption behind this research. Instead, the presented research process was based on constant compilation, juxtaposition and coupling of various voices and perspectives - statements and behaviors of blind individuals, my observations and conjectures, gradually emerging categories and generalizations, results of other studies on disability and theoretical concepts of various authors (see Denzin, Lincoln 2005: 4-6). In this context, the choice of specific interpretative tools or theoretical reference points depended 
on the extent to which they were stimulating and useful for a reliable description of the lives of study participants, and more generally - the lives of congenitally blind individuals.

Steering the research in such a direction led me to distinguishing three essential, interrelated dimensions of the lives of the blind people, which to a large extent make up the specifics of their social and cognitive situation. It is about (ab)normality, (dis)ability and sight(less)ness ${ }^{2}$. The overall results of my explorations are expressed in the doctoral thesis and a monograph prepared on its basis, awaiting publication in 2019 (Pietrowiak 2019). In this article I will present only a sample of these investigations, focusing on the relationship between norms and values of visual culture, the scientific and common definitions of blindness and the imaginings that blind individuals have of the basic visual skills and phenomena. I believe such a selection will bring closer both the nature of current research conducted in this field and its further possibilities, with focus on the border area between disability studies and anthropology of the senses.

\section{Visual Culture}

In the humanities and social sciences, the visual activity of human beings is most often described using the category of visual culture, which - I think - is useful as long as it does not limit the notion of visuality to images, representations and pictures (Ingold 2011: 316). Its broad definition was formulated by Nicholas Mirzoeff (2015: 10):

Like history, visual culture is both the name of the academic field and that of its object of study. Visual culture involves the things that we see, the mental model we all have of how to see, and what we can do as a result. That is why we call it visual culture: a culture of the visual. A visual culture is not simply the total amount of what has been made to be seen, such as paintings or films. A visual culture is the relation between what is visible and the names that we give to what is seen. It also involves what is invisible or kept out of sight. In short, we don't simply see what there is to see and call it a visual culture. Rather, we assemble a worldview that is consistent with what we know and have already experienced.

According to William J.T. Mitchell (2005: 337), the purpose of such reasoning is "to overcome the veil of familiarity and self-evidence that surrounds the experience of seeing" and to highlight its social, cultural and biological determinants. More specifically, research in this field consists of revealing the acquired and embodied ways of seeing, showing their relativity and interdependences, as well as tracking the relationships between everyday practices and the values

2 In the Polish language, the most common term for an individual who lost the ability to see is the word "niewidomy". Its literal translation into English would be "non-sighted" or "sightless". The word "ślepy", which can be considered the closest equivalent to "blind", is perceived as a biased, unfair and inappropriate expression referring to this group of people (see Deshen 1992: 1-2). 
assigned to vision. As Mitchell (2005: 345) accurately adds, analysis of visual culture cannot be limited to presenting its cultural determinants - "it is not just that we see the way we do because we are social animals, but also that our social arrangements take the forms they do because we are seeing animals".

The coupling of certain forms of viewing and seeing with ways of thinking and acting is revealed in many areas of human life, what is then reflected in the multitude and diversity of works on visual culture (Brennan, Jay 1996; Heywood, Sandywell 1999; Jenks 1995; Kurz, Kwiatkowska, Zaremba 2013; Mirzoeff 1999, 2002; Rampley 2005; Robins 1996; Smith 2008; Stocchetti, Kukkonen 2011). What differentiates and inspires researchers in this field are varying opinions on the status of visuality in the modern world. Speaking more precisely, as Łukasz Zaremba (2016: 9) suggests, "the dispute is on whether contemporary, late modernity or modernity period in general (from the invention and popularization of photography) is exceptional in terms of the visual: is it an era of visual culture, meaning that vision and the visible dominate or at least enjoy certain privileges." A negative answer to such a question is provided, among others, by Mitchell (2005: 349), who writes:

It should be clear, then, that the supposed "hegemony of the visible" in our time (or in the ever-flexible period of "modernity"; or the equally flexible domain of "the West") is a chimera that has outlived its usefulness. If visual culture is to mean anything, it has to be generalized as the study of all the social practices of human visuality, and not confined to modernity or the West.

Mirzoeff adopts a different attitude, emphasizing the unprecedented dynamics of change in the perception, creation and processing of various types of images, as well as their impact on everyday practices, interpersonal relations, issues of identity and power:

Like it or not, the emerging global society is visual. All these photographs and videos are our way of trying to see the world. We feel compelled to make images of it and share them with others as a key part of our effort to understand the changing world around us and our place within it (Mirzoeff 2015: 5).

Regardless of the varying ideas on how to resolve this issue, it is difficult to find arguments that would deny the importance of sight and vision in the development of the human world - both in the context of the evolution of the species, as well as regarding the lives of communities and individuals. In this sense, the authors who criticize the ocular-centric orientation of the contemporary period and Western civilization, do not truly deny the impact of visuality on various areas of life, but rather try to visualize the existence and significance of the different dimensions and systems of human perception, overlooked so far (Classen 1993; Classen, Howes, Synnott 1994; Geurts 2002; Howes 2005; Howes, Classen 2014).

Such a change in perspective would be a counterbalance to the analyses pursued by the researchers blinded by visuality, who fail to see that they 
themselves highly represent and reproduce the Western way of thinking about perception (Classen 1998: 143; Howes 2003: XII-XIII). At the same time, exploring the multi-sensory or extra-visual ways of cognition can sober up the constantly watched and observed representatives of Western culture, restore their psycho-physical balance, and reunite them with themselves and the world (Pallasmaa 2009; 2012).

I have no doubt that the attempts to describe different sensoria and ways of using different dimensions of cognition are extremely valuable, refreshing, touching on the important issues of mutual understanding or the translatability of cultural perspectives. Problems occur when the motivation behind these attempts is to challenge the Western organization of the sensorium and to supersede the sense of sight, the value of which is treated as an obstacle to a multi-sensory experience of the world.

I believe that assessing the sense of sight as too dominant or too absorbing may result from a certain sense of "boredom" with the topic of visual culture, which is again now, after a certain boom for research, being perceived as something obvious, banal, uninteresting. In this sense, identifying researchers who focus on the topic of visual perception as "epistemological imperialists" (Howes 2003: 239-240) is a manifestation of ethno-marginalization - understood as the opposite of ethnocentrism - that changes scientific observation into multi-sensory judgments. Tim Ingold (2011: 316), who has become the target of this type of allegation, comments:

Eyesight is quite obviously important to most human beings everywhere, and to accuse anyone who chooses to write about it of having succumbed to western ocularcentrism is about as absurd as banning research on human toolmaking and tool-use on the grounds that it amounts to collusion in the modernist project of technological world-domination!

To summarize the topic: the significance of the sense of sight for the development of human species, group and individuals results not only from the biological conditions of the human body, but also from the socially developed perception system that determines the general hierarchy of senses and detailed rules for their use. It is the specific patterns of cognition and experience that establish the relationship between visuality and social norms and practices, thus constituting an important subject of anthropological or sociological research. At the same time, contrary to the opinion of some anthropologists, emphasizing the evolutionary and cultural significance of the sense of sight does not necessarily lead to the negation of the multi-sensory character of human perception; on the contrary - the study of specific visual practices may lead to the re-embodiment of visuality, perceiving it as one of many dimensions of human cognition and action and revealing its (non)obviousness. 


\section{Theories of Blindness}

It seems quite obvious that the social situation of blind people depends to a large extent on the values and functions that are attributed to the ability to see in a particular cultural community (Walthes 2007: 14). In this sense, perceiving blindness as deep disability and limitation results directly from the assumption that eyesight has key significance for independent and effective functioning in the world. As indicated by many authors, this assumption is particularly important for the development of Western culture, in which the sense of sight has been defined as the most perfect and irreplaceable tool of cognition, providing people with a faithful representation of reality (Jay 1993; Warnke 1993). Taking this view further, vision is associated with knowledge, visuality with obviousness, light with consciousness, eye with mind (Jenks 1995: 1; Pallasmaa 2012: 18-19). Logical consequences of such assumptions are the widespread fear of losing sight, treating blindness as one of the toughest punishments, relating blindness with ignorance, spiritual death and mental darkness (Barash 2001; Kinash 2006: 4-5; Monbeck 1975: 135-142; Wheatley 2010: 129-154). As summarized by Georgina Kleege (2010: 60-61):

Blindness is usually understood to be a lack, an absence, a void. Since seeing and knowing are so often conflated in people's thinking, blindness is defined as the opposite of knowing, a state of non-knowing. People speak of losing sight, never of gaining blindness. For this reason, blind people are thought to be cut off from reality, cut loose, adrift. While we may use our other senses to get around and identify objects we encounter, our knowledge of the world is assumed to be incomplete, flimsy, and makeshift - a poor imitation of true knowledge.

Works by authors inspired by the phenomenological concepts of human experience and the ideas of social constructivism (Friedman 2016; Gobo 2009; Scott 1969; Walthes 2007) attempt to overcome the theory of non-seeing targeted this way. A similar perspective is adopted by some blind writers and researchers who try to reflect the specificity of their own experience and capture their non-visual nuances (Kleege 1999; Michalko 1998). As John Hull writes (2001: XII):

Blindness does not in principle lead to the fragmentation of life. The lives of blind people are more or less as integrated as the lives of sighted people. It is true that we tend to think of sighted people as having something which blind people lack, and in that sense blindness is considered to be a deficiency. (...) Nevertheless, the life of a person who is blind is experienced as a whole. Losing one's sight is not quite like losing a limb. The blind person does not always remain conscious of something missing. (...) One should not think of the life of the blind person as a cake which has had a slice cut out of it. Rather, it is like a smaller cake. It is experienced as being intact, although the scope of activity has in many ways become smaller.

It is my belief that phenomenological approach opens up interesting research and interpretation possibilities, especially in relation to the situations 
and dimensions of blind peoples' lives in which lack of sight loses meaning and becomes imperceptible, which, in turn, allows these individuals to act in accordance with their own skills, needs and preferences (Kleege 1999: 4). In addition, putting emphasis on the specificity and cognitive potential of blind people is an undoubted empowerment factor: since they learn the world in a different, specific way - which is neither worse nor wrong - they should be perceived as positively different, and not impaired, unequal or lacking qualities.

At the same time, I argue that such a targeted perspective has its own limitations and can be useful only as long as it does not take blind people out of the real environment of their lives, which are shaped by numerous and significant relationships with sighted individuals, who inspire the way blind people think, act, communicate, or shortly: find their way in reality (Vaughan 1998: 20-21; Kleege 2005). In other words, regardless of what kind of assessment we make regarding this particular state of affairs, it is the historical and social process of labeling blind people that sets the basic framework for their functioning and thinking, and thus affects the form and content of their sensations and experiences.

Furthermore, the definition of blindness is not only the effect of the high value attributed to visual culture, but also of universal and biological character of sight. Broadly speaking, the sense of sight constitutes the norm for our species and is an innate property of humans, thanks to which the evolution of humanity took a turn in this and no other direction. Thus, as Zaremba accurately states (2016: 8), "it is impossible to dissect visuality from culture or from the world, as it permeates all their dimensions and is one of the basic matters. Without it, the world would 'look' completely different".

With this brought to light, blindness necessarily appears as a damage to a specific function of the organism that prominently affects the lives of individuals, but does not make them a separate cultural group, living in accordance with their own, autonomous perceptual patterns. With that assumption in mind, Maria Grzegorzewska (1964: 77, 79), the founder of the Polish typhlological school, arrives at the following conclusions:

Blind people are brought to the world of those able to see, with accident only to become the cause of their disability. Therefore, blind individuals bear all the traits disinherited from their ancestors, each of them being one of the links in the great chain of beings, just like we are all products of centuries-old evolution and culture, so it has all the developmental benefits, including visual ones. (...) It is obvious that a blind person does not adapt to his or her own world, that is to the world of the blind, but that all his aspirations run towards mastering the world of those able to see. (...) Blind individuals want to belong to the society of the sighted, they want to be active members of this community, they are interested in the world of seers and understand this world.

Importantly, likewise the phenomenological approach, the above theory too has an emancipatory and educational dimension. Firstly, it attempts to include blind individuals in "our" world, as "one of our kind". Secondly, it is a way 
to challenge the perceptions that would limit them to be perceived as inhuman, morally corrupt, stupid and punished by God (Lowenfeld 1975: 5-24; Monbeck 1975: 22-65). In this case, however, stating that the blind people are "fully able" is not the effect of broadening the limits of normality, which would cover the forms of human experience previously perceived as "pathologies" (inclusion through appreciating otherness), but results from seeing them as "almost as good as the sighted" or as "the sighted who became blind" who under certain conditions can become "just like us" (inclusion by denying otherness) (see Douglas 1984: 37-41; Michalko 2002: 63).

According to the above theory - partly overlapping the common perceptions of blindness - in order to find their feet in the "sighted world", blind people must undergo visual rehabilitation: a process in which they realize their own cognitive limitations and show a desire to adapt to the standard and approved ways of reality (Scott 1969: 19). The process of adaptation necessarily takes place under the watchful and controlling eye of the sighted, cast in the role of the "normals", that is representatives of the dominant culture and of the normative reference group (Goffman 1963: 4-5).

However, while the lack of eyesight is a key determinant of the identity of blind individuals, and the "sighted world" creates appropriate space for their lives and socialization, the "sighted" themselves do not realize their supremacy, do not define themselves in this way, do not contemplate the value and ordinariness of seeing (Michalko 2002: 49; Titchkosky 2003: 50). In other words, while sightless individuals are generally reduced to the role of the blind, and therefore defined primarily through the absence of a certain property, the sighted people are aware of having the ability to see - and consider it as an ability - only in the event of sudden visual impairment or during sporadic contacts with "non-sighted" people. As Rod Michalko (2002: 38) comments:

The "world of the normal," that is where I become blind, that is where I am blind. Even though such a world is not an obviously empirical one and thus is one constructed out of particular interests and values, it is the world in which I live. The "world of the normal" is the background against which stands the figure of blindness. This world depicts itself to me as "sighted," now that I am blind. Of course, the world is not sighted, nor is it blind. It does have blind people and sighted people in it, however, and since this "world of the normal" thinks of sightedness as the normal state of affairs and blindness as not, it becomes the "sighted world".

In this context, compliance with the established laws of visual culture becomes the social duty of blind people, if they want to be recognized as fully able members of society. Physical lack of sight does not exempt them from the obligation to participate in the cultural community of looks, images, colors and pictures. On the contrary: knowing and adhering to visual bans and orders is a condition for their social acceptance, a measure of normality and maturity, as well as a way of "catching up with the sighted", "being like a sighted person". 
To sum up, on the one hand, the lives and perspectives of blind individuals are shaped by the cognitive abilities of their bodies, and on the other hand, by the reality they share with others, whose essential element is the obviousness, the significance and the community-making quality of sight. This duality is echoed in the theoretical models of blindness, as well as in the social ideas that explore the subject, stressing either the potential and uniqueness of blind people's experience or their physical impairment and the need to reduce its negative consequences. In this context, finding oneself in the world requires blind individuals to develop non-visual modes of acting and gathering information, as well as to learn and respect the visual norms and values that are valid among the "sighted", treated as the superior and proper reference group (Deshen 1992: 24).

\section{The Secrets and Puzzles of Visuality}

The necessity of living in a world constructed by and for the "sighted" leads to a situation where - as Kleege notes (2005: 179) - "the average blind person knows more about what it means to be sighted than the average sighted person knows about what it means to be blind". Although this disproportion is largely the result of the minority status attributed to blind people, who must adapt to the rules shared by the "normal", "sighted" majority, their spontaneous curiosity and inquisitiveness, stimulated by the simultaneous ubiquity and inaccessibility of vision, play an important role in this perceptual rehabilitation - as confirmed by Michalko (1998: 82):

Eyesight is a curious thing for persons who are blind, especially for those who are congenitally blind. In fact, blind persons are more curious about eyesight than are those who see. Persons who see typically take eyesight for granted and are not curious about it or about their seeing. Curiosity occurs only when eyesight cannot be taken for granted, such as when blindness occurs or when someone does not see in the same way she or he did before. But, for the most part, curiosity about eyes is restricted to those who experience the 'mystery of the eye' through the 'shadow of blindness'.

In practice, exploring the secrets of visuality is an extremely tedious, complicated and sometimes frustrating task. The lack of or significant limitation of the sense of sight makes visual socialization - often seamless when based on the observation and imitation of other people - becomes a series of cognitive puzzles, solved with the help of overheard information, analogies, speculations, experiments, suspicions (Friedman 2012: 294; Saerberg 2010: 371-372). In this context, visuality ceases to be the "natural" and "real" image of the world absorbed in the blink of an eye, and instead becomes a collection of illegible instructions and abstractions, a faded map filled in along the way with individual points and routes.

The first step in this journey is the discovery of one's own dissimilarity with other people which turns out to have a fundamental, qualitative character. In 
some cases, this happens due to incomprehensible reactions and statements of people representing various degrees of closeness to the blind individual, who refer to the "abnormality", "illness", "disability" or "unhappiness" of a sightless child.

Witold $^{3}$ : I remember one particular scene from my childhood - someone mentioning my name and adding this strange word: "blind". As soon as possible, I asked my mother what was going on. She explained to me that I could not see which is why I was called blind. Her explanation did not work for me, so I said: "But mom, I can see". And only then, as my mum responded, I experienced the shock: "Well, you do see a little, but only a little. Our sight is much, much better than yours". Until that moment, I had been convinced that everyone could see the world just like me. When I tried to imagine what it was like to see "much better", it turned out to be beyond my capabilities.

At other times, the source of astonishment for blind people is observing significant differences between their own bodies and the bodies of their closest relatives - parents, siblings:

Paweł: As a little boy, I thought that my mother was also taking her eyes out of their sockets for the night. When I found out she did not have to do that, I asked what her eyes were made of. She explained that her eyes were alive. And whenever I wanted to touch them, she closed her eyelids, so I could not do it. Mum told me too that I used to have eyes like hers, but they became sick. Her explanation was not sufficient enough for me, I had to get more information. I once tricked her and somehow managed to touch her eye. I found out that it was soft and made of flesh. I thought then that such eyes must be slightly worse than mine, because they could be broken and could not be removed and properly cleaned. I remember that this realization disappointed me.

The key moment of this process is to realize the abilities and benefits that result from being able to see and as such are only available to the "sighted". At the same time, this discovery creates a strong need for further exploration, cognitive experiments and tests aimed at answering the basic questions: What exactly does "seeing with eyes" mean? What can one actually see? When can one see something? (Magee, Milligan 1995: 8-9).

Paweł: I remember that strange feeling: my parents were reading newspapers, and I looked at them and saw only blank pages. I asked: "How can you even read this? Is anything written in here? Where does it say?" And my mother said she was able to see the writing and read it. I was 5 years old. To understand this, I did different experiments when my mother went on reading the newspaper. I covered the pages for her, took them away, reversed them upside down. And that actually resulted in that she could not read anymore. I realized then that

3 Some research participants are quoted under their real first names. Others asked for their names to be replaced with pseudonyms. At the same time, all written comments made by the participants are presented under their real first and family names. 
this was something that I could not experience. My mother said that when I went to school, I would learn how to read.

Although similar explorations allow for gathering specific information about sight - its scope, conditions and applications - they do not make it less puzzling and do not provide a sense of confidence and understanding. This also applies to the basic potentials of sight, such as recognizing objects and people at a distance, and moving freely in unfamiliar spaces (Magee, Milligan 1995: 8).

Barbara: I cannot imagine what seeing is like. It puzzles me that people can see something located so far away. My mother sees what is happening at the bus stop, even though we are at the other end of the street. If I cannot hear something, then it means it is far away for me.

Katarzyna: I cannot comprehend the fact of seeing. For me it simply abstract. Sometimes I have the impression that you all are just joking around with us. How can you go and see someone on the other side of the street, and recognize that it is this or that person, when they are not saying anything? How is that possible? I do have a problem with it.

In addition to the skill of "visual prediction of the future", the issues related to the concept of perspective and the possibility of presenting three-dimensional objects in the form of two-dimensional images are also a puzzle (see Heller, Ballesteros 2006: 6; James et al. 2006):

Katarzyna: I still do not understand how does it work do watch a football match on TV, with 22 guys inside such a small box. You can see the players, the ball, the viewers, the commentator. How do they all fit in there? If a guy is two meters tall, how tall is he on the screen? Is he also two meters tall or less? (...) And I do not understand at all how you can present a three-dimensional object on a flat piece of paper. How can you draw a cat, for example? I will bring you a cat and put it on your lap. Now - how is it that you will paint this cat on a piece of paper? Will you paint it without the forelegs? Or without the rear? Which side will you slice off? I cannot get it. You have a piece of paper and here you paint the head, then the legs, back and tail. But why are you drawing the cat from the side? What about its eyes and nose?

Colors, their perception and recognition are a perplexing concept as well:

Barbara: The colors are also quite puzzling. I try to understand the concept, but I simply cannot describe it. It happens that I forget what colors my clothes are. And if someone talks about strange colors like "coral", I am unable to associate it with anything at all. I do not associate this color with corals, because color is something different than corals.

Katarzyna: Please, tell me, what is blue? What does the blue color look like? These are the questions that make people wonder. What does the orange color look like? I associate it with an orange that I can touch, nothing else. But what does 
it look like? If you say that it is warm, it does not tell me anything. In my opinion, colors cannot be explained to someone who cannot see. I have been asking these questions to most people I know, and no one has been able to explain to me even one single color. They told me that blue is a cold color, just like water. Okay, but what does it look like? It is a constant discussion about something that to me is pure abstraction.

What is worth noticing, despite being abstract and illegible, the "world of colors" significantly stimulates the imagination of individual interlocutors, in particular women - it speaks to their emotions, and affects their choices and behaviors in unexpected ways:

Barbara: When I was a small child, I could not stand being around red things. I hated that color. And our educator, who also had lectures with students of pedagogy, even gave my example in class. He said that one should not cheat the blind, but it would indeed be possible to tell me that a red blouse was, for instance, blue and I would wear it then. I have no idea why I hated red so much. Actually now it has changed to the contrary - I like red things.

Broadly speaking, the basic way to overcome the opacity and intricacy of visuality is to translate it into the language of one's own feelings and sensations. What is extremely important, blind people are more often trying to understand the visual phenomena by analogy to the sense of touch, and not - as it might seem - the sense of hearing, which, like eyesight, allows recognizing objects located at a considerable distance from the learning subject.

Emilia: I just cannot imagine seeing. I know that people have the sense of sight, which means they have eyes that touch objects. People with eyesight can touch objects with their eyes, same like I can touch things with my hand. The sighted are able to touch an object with their hands too, but I suspect that they do not feel it quite the same as I do, because they have seen it already before and have some preconceptions about it because of that. They can know, without putting their hands on an object, whether something is smooth or rough. I do not see qualities like that with my eyes, so I experience it differently by touch. The fact that you can touch something with your eyes gives you a picture of the object, creates a picture in your head ${ }^{4}$.

Similar associations emphasize the importance of touching, stroking, caressing, holding, grasping and embracing in how blind individuals interact with their physical surroundings (Paterson 2006). At the same time, these connotations bring to mind the intuitions of philosophers and perception researchers, according to which the eye not only works in conjunction with the experience of the world's tangibility, but also - like all senses - it is a subtle form of touch, understood

\footnotetext{
4 Another example presenting "tactile thoughts" on the ability to see is a situation where Artur, one of study participants, was, just for fun, pretending to read a newspaper like a "sighted" person - to do that he placed a piece of paper right onto his eyes and started moving his head from left to right.
} 
as the primal, irreducible feature of living organisms and even the condition for human thought processes (Howes 2003: 12). As Juhani Pallasmaa (2009: 92) writes about this topic:

Our contact with the world takes place through the skin of the self by means of specialised parts of our enveloping membrane. All the senses, including vision, are extensions of the tactile sense; the senses are specialisations of skin tissue, and all sensory experiences are models of touching, and thus related to tactility.

"Thinking through touch" or "thinking with hands" is particularly showing in situations when individual interlocutors make attempts to explain how they imagine visuality in the context of movement and exploration of space:

Piotr: I can imagine that when you, a person able to see, start walking, the landscape is changing in front of your eyes. What you see is just constantly changing. I am not imagining that the world around us is visible. I believe it only becomes seen when I concentrate on it. I can also imagine that if I looked, for example, to the right, then I would see the things I pass by, but would not be able to see in the distance, as it would only become clear once I approached it. I have no idea how I would be able to process all that at once - things that are close, other things that ate far away or behind me. But right, I would not be able to see behind my back. Although it is possible to catch a glimpse of something in the corner of one's eye. For me, it would completely overload my brain and stop me from being able to focus on anything really. If you can see everything, what are you supposed to focus on actually?

Similar observations can be directly related to the sequential nature of tactile cognition, in which knowledge of a given object increases gradually and not all at once which is the case for visual perception (see Hollins 1989: 57-58). Therefore, research participants perceived "seeing everything at once" as an unmanageable mass of visual experience, and thus considered it incomprehensible and impossible to translate in their own ways of experiencing the world. The feeling of this incompatibility was revealed in a statement made by Paweł during sailing regatta integration event:

Pawel: I understand theoretically what you are saying about the landmarks used when entering the port, or when we take a course on an island, but I would be able to fully comprehend it if my hands were 20 meters longer and I could use them to touch it all.

Significantly, a similar statement is quoted by Denis Diderot (2011: 176) in the famous essay Letter on the Blind for the Use of Those Who Can See, published for the first time in 1749:

One of us decided to ask our blind man whether he would like to have eyes. $\mathrm{He}$ replied, 'If I wasn't so curious, I'd just as well have long arms, as it seems to me that my hands could teach me more about what's happening on the moon than 
your eyes or telescopes can, and besides, eyes stop seeing well before hands stop touching. It would be just as good to improve the organ I already have, as to grant me the one I lack'.

As shown in research, this approach is shared by people who - being aware of the benefits coming from the ability to see - do not treat themselves as lacking anything or disadvantaged in any way. Thus, to the disbelief of the sighted, they do not feel a constant desire to regain the ability to see, to "open their eyes", and instead prefer to settle on their own ways of learning and describing reality carefully developed, tested in practice, giving them a sense of control.

Emilia: I am aware that sight is crucial for most people. Some people shared with me opinions that it is better to have cancer than to be blind. Perhaps people think that because being able to see is convenient, it makes life easier. Seeing happens in a second, just like that. On various occasions, people said to me: "I see" as if it explained everything to me. You see - so what? How do I know what you see and how do you see it? Sometimes, just in case, I prefer to explain things as if everyone were blind. For example, when I explain the way to my dorm, I never say: "You will get off at the bus stop and see a big PIAST sign on a gray, big building", Because I do not know when this sign becomes visible. I have no idea how it is seen. That is why I would rather say that there is an advertising post next to the bus stop, which you can definitely see from a close distance, and that after the post you have to turn right. For me this is more adequate.

Grzegorz: I would not like to regain sight now. I would like to be able to check something with sight at times, but on the principle of an on/off switch: I would check the appearance of certain things with my eyes and then return to my basic status.

In addition, individual participants of the research imagine the hypothetical situation of regaining vision as a very risky, threatening loss of feelings of certainty and security, equaling the entrance into the world of chaos and sensations beyond their understanding. Importantly, such associations coincide with the described cases of real vision recovery and the related disorders, difficulties and uncertainties (Paterson 2007: 33-34; Sacks 1996: 108-152).

Piotr: In general, I am not sure if I would like to be able to see. I would only like to see the few people and few places that are stuck in my mind. Yes, that I would like to see. But overall, I do not know if I would like to be able to see all the time, because it would turn my life upside down. I would have to learn everything all over again. I really do not know if I would like to regain sight.

Aleksandra: I do not need to have my own an opinion about sight. I have no such need. Sometimes people ask me, if I would like to be able to see. And you know what? I do not have a definite answer to this question. It seems stupid to say no, because they would probably think I am some silly woman who does not know what she is talking about. But on the other hand, it seems to me that if 
I miraculously regained my sight now, I would not be able to embrace it, I would be in absolute shock, unable to function normally. I am afraid it could even make me lose my mind.

Summing up the collected examples: when faced with the abstraction and illegibility of visuality, blind people can experience simultaneous feelings of fascination and resignation, the desire to explore the mystery of the "most important sense", as well as the need to limit themselves to their own ways of managing reality that give them control and relative independence. At the same time, despite the awareness of the benefits and advantage of the "sighted" individuals, some of the interlocutors do not express a desire to regain sight, which to a certain extent results from the understanding of visuality as a mass of sensations, which ultimately leads to distraction and weakening of other senses.

\section{Conclusion: Blind People in the "Sighted World"}

According to the overall results of this study, the participation of blind people in visual culture is not limited to their knowledge of the basic phenomena and visual skills discussed above. Aside that, their "visual rehabilitation" takes the form of other training exercises and duties.

First of all, out of necessity, blind people learn the "language of the sighted", i.e., the many common and diverse expressions, phrases and metaphors that refer to the field of sight and vision itself. Speaking the "language of the sighted" allows them to adjust to the "sighted world", to gain knowledge about the principles, rights and duties ruling that world, i.e., to explore the secret of visuality (Kleege 2005: 184-185). A learning process that is targeted that way happens on two levels. On the one hand, blind people receive direct and purposeful hints on how the sense of sight operates in general, as well as learn about the individual visual phenomena. On this level, the information typically comes from the people in their closest environment, who try to explain what it means "to see", respond to questions that keep bothering the blind, reduce their sense of cognitive confusion, to share with them and instill in them the norms and behaviors governing the sphere of appearance and image (see Koster-Hale, Bedna, Saxe 2014: 75). On the other hand, knowledge about the meanings and values assigned to sight is contained in the language itself, since it reflects the shared sensorium, or, more broadly, as pointed out by Wojciech Burszta (1998: 67), "the conceptual, structural scheme of a given culture" (see Sendyka 2011). On this level, it becomes crucial to listen carefully to the statements made by the "sighted", to register situations in which sentences related to seeing, appearance, eyes, light or color are used, or to capture the sense of visual expressions in relation to their usage (Landau, Gleitman 1985: 97, 171; Magee, Milligan 1995: 9).

Secondly, blind people must address the rich field of images and various visual representations that play a significant role in communication and entertainment. 
In blind individuals, these representations provoke various interpretations and reactions, spanning between two basic attitudes. The first attitude is characterized by curiosity of the content of various types of images and the ways they are used, by activity in acquiring visual information or skills, and by the conviction that they constitute a valuable source of knowledge about the "sighted world" and a useful tool in the process of achieving "normality". The second attitude is characterized by strong skepticism and doubt that it is possible to achieve an adequate understanding of visual representations and to include them in their own lives - emotions, needs, interests; in this case, the ubiquity of images appears to be a form of symbolic violence on the part of the "sighted" who require the blind to adapt to their abstract customs and fascinations.

Thirdly, the main visual puzzle for the congenitally blind people and at the same time the source of their everyday concerns - is the visuality of the human body, as it has fundamental significance for the sense of identity, classification of other people, and the course of everyday interactions. The mirror-like nature of vision undoubtedly shapes the practices and emotions of the blind individuals, who, being unable to reciprocate and control the gazes coming from others, become the perfect objects for unpunished, even aggressive viewing. Having recognized this visual subordination, sometimes abused by the gazes of the "sighted", blind people try to understand its foundations and consequences, as well as develop their own methods of resistance to this kind of violence and control.

Fourthly, a significant moment in the visual socialization process of congenitally blind people is the discovery of the judgmental function of how people look at each other; a function that allows the "sighted" not only to recognize the gender or age of other humans, but also to rank them in terms of attractiveness or physical fitness. This ability also enables to notice the specific attributes of blindness: a white cane, the presence of an assistance dog or a guide, obscure or cloudy eyes. The visibility of these elements can both improve the course of a meeting, providing its participants with useful interactional guidelines, as well as focus the attention of the sighted on the differences and "abnormalities" of the blind, as well as induce incompetent and stigmatizing comments (see Hammer 2012; Kleege 1999: 19; Magnusson, Karlsson 2008).

Fifthly, and lastly, an essential step in the process of the visual rehabilitation of congenitally blind people is the assimilation of the values and meanings attributed to gestures and facial expressions, as well as the understanding of the principal significance that eye contact has in direct interaction. "Sightless" absorption of specific gestures, attitudes and facial expressions resembles learning a foreign, unnatural and highly formalized language; learning that ultimately does not ensure proficiency in its use, and instead often increases the awareness of one's own incompetence and otherness. This feeling is reinforced by additional restrictions on the "abnormal" impulses of blind people - usually referred to as "blindisms" - which are their specific ways of responding to strong emotions and unique stimulants that help achieve inner peace or concentration. As 
a consequence, the sphere of facial expressions and gestures can be fascinating and intriguing for the blind. At the same time, the social value of this area forces them to use continuous visual control: its purpose is to prove their own normality and familiarity with the rules of cohabitation, while the result is the abandonment of the more comfortable, non-visual ways of using the body.

The above observations and conclusions allow us to verify William Mitchell's statement (2005: 349), according to which "To live in any culture whatsoever is to live in a visual culture, except perhaps for those rare instances of societies of the blind, which for that very reason deserve special attention in any theory of visual culture". While the postulate to cover the lives of the blind with "special attention of the theories on visual culture" does itself coincide with the purpose of the presented research, the image of a closed community of blind individuals, independent and separated from the rest of the world, has nothing to do with the life of the participants of this research, and becomes a tool useful only in literary or film fiction (see Wells 1995).

At the same time, the fact that part of the sensory experiences shared by the participants of my research is distinct and non-transferable leads to a situation when a road towards mutual understanding between blind and sighted people becomes obscured somehow halfway, producing curiosity or even fascination, hence leaving both groups clearly unsatisfied. Being aware of the limitations of the above description, I believe that it allowed to partly reveal the specificity of the (non)visual experiences shared by the described people, and at the same time to "show seeing", rediscover its unobvious features and to invite the sighted readers to take a closer look at how they view the world (see Friedman 2012: 286; Titchkosky 2003: 53).

\section{Comments from Research Participants}

Grzegorz Modrzyński: When it comes to dreams about regaining vision, one should clearly distinguish the congenitally blind from those who became blind later on. While congenitally blind individuals may not feel the need to regain their eyesight - as the saying goes, "what the eye doesn't see, the heart doesn't grieve over" - for people who lost the ability to see, aware of what they are actually missing, regaining sight will become an object of greater or lesser desire, calling in various life situations.

Witold Strugała: In your writing, you say that the blind people you know do not dream about regaining sight. Indeed, I also do not feel a constant desire to be able to see again, which often surprises my sighted interlocutors. My life is not endless path of suffering and I do not live in the waiting for a miracle or a medical breakthrough, as imagined by many people who are able to see. At the same time, as a person with residual vision, I would by all means welcome an improvement of my eyesight. It seems to me that research conducted among people who see slightly more than just light could give somewhat different results, because visual 
impressions, however reduced, are not something unfamiliar and inconceivable for us. However, I for sure cannot speak for all "residuals", so this comment covers only my own perspective.

Sandra Tworkowska: I told you once that in my stories I do not write about blind people. I believe that the partial reason behind this is that it would cause me more problems than writing from the perspective of a sighted character. If I find it difficult to describe a given room, a certain space or someone's appearance, I will create something makeshift to investigate it later: I can always search the Internet for information on a given style of interior design or fashion - I have access to quality "templates", which I can quickly turn into pieces of my original work. But if I were to describe the world of a blind person, it would require much more effort. I have the impression that I would have to work hard to create something that would be interesting both for me and for the potential recipient, something highly aesthetic and using varied language. The point here is that the lack of sight is not really a topic for me. More often it complicates matters than helps create an exciting story. Lack of sight in a character who is also struggling with other issues interferes with how the main thought is expressed, or, to put it in a lofty way, with the message behind the text.

Emilia Stalmach: No one has the right to impose their standards on the world. No one has the right to determine what is normal and what is not. For me, it is normal that I had learnt the world with the help of smell, hearing, touch, taste and all the other ways that I have developed in myself thanks to being blind. When a sighted person apologizes to me for having used a vision-related phrase in my presence, I feel very sorry for him or her. Because in fact, it is that person and not me - who feels uncomfortable.

Translated from Polish by Ewa Pater-Podgórna

\section{References}

Barasch, M. (2001). Blindness. The History of a Mental Image in Western Thought. London New York: Routledge.

Brennan, T., Jay, M. (eds.) (1996). Vision in Context. Historical and Contemporary Perspectives on Sight. New York - London: Routledge.

Burszta W.J. (1998). Antropologia kultury. Tematy, teorie, interpretacje. Poznań: Wydawnictwo Zysk i S-ka.

Classen, C. (1993). Worlds of Sense: Exploring the Senses in History and Across Cultures. London - New York: Routledge.

Classen, C. (1998). The Color of Angels. Cosmology, Gender and the Aesthetic Imagination. London - New York: Routledge.

Classen, C., Howes, D., Synnott, A. (1994). Aroma: The Cultural History of Smell. London New York: Routledge.

Denzin N.K., Lincoln Y.S. (2005). Introduction. The Discipline and Practice of Qualitative Research. In: Denzin N.K., Lincoln Y.S. (eds.), The Sage Handbook of Qualitative Research. Third Edition (pp. 1-32). Thousad Oaks - London - New Delhi: Sage Publications. 
Deshen, S. (1992). Blind People: The Private and Public Life of Sightless Israelis. New York: State University of New York Press.

Diderot, D. (2011). Letter on the Blind. In: K.E. Tunstall, Blindness and Enlightenment An Essay (pp. 164-227). New York - London: Continuum.

Friedman, A. (2012). Believing Not Seeing: A Blind Phenomenology of Sexed Bodies. Symbolic Interaction, 35 (3), 284-300.

Friedman, A. (2016). "There are two people at work that I'm fairly certain are black": Uncertainty and Deliberative Thinking in Blind Race Attribution. The Sociological Quarterly, 57(3), 437-461.

Geurts, K.L. (2002). Culture and the Senses. Bodily Ways of Knowing in an African Community. Berkeley - Los Angeles - London: University of California Press.

Goffman, E. (1963). Stigma; Notes On The Management Of Spoiled Identity. Englewood Cliffs: Prentice-Hall.

Grzegorzewska, M. (1964). Wybór pism. Warszawa: PWN.

Hammer, G. (2012). Blind Women's Appearance Management: Negotiating Normalcy between Discipline and Pleasure. Gender \& Society, 26 (3), 406-432.

Heller, M.A., Ballesteros, S. (2006). Introduction: Approaches to Touch and Blindness. In: M.A. Heller, S. Ballesteros (eds.) Touch and Blindness. Psychology and Neuroscience (pp. 1-24). Mahwah: Lawrence Erlbaum Associates.

Heywood, I., Sandywell, B. (eds.) (1999). Interpreting Visual Culture. Explorations in the hermeneutics of the visual. London - New York: Routledge

Hollins, M. (1989). Understanding Blindness. An Integrative Approach. Hillsdale: Lawrence Erlbaum Associates.

Howes, D. (2003). Sensual Relations: Engaging the Senses in Culture and Social Theory. Ann Arbor: University of Michigan Press.

Howes, D. (ed.) (2005). Empire of the Senses. The Sensual Culture Reader. Oxford - New York: Berg.

Howes, D., Classen, C. (2014). Ways of Sensing. Understanding the senses in society. LondonNew York: Routledge.

Hull, J.M. (2001). On Sight and Insight. A Journey Into the World of Blindness. Oxford: Oneworld.

Ingold, T. (2011). Worlds of sense and sensing the world: a response to Sarah Pink and David Howes. Social Anthropology, 19 (3), 313-317.

James, T.W., James, K.H., Humphrey, G.K., Goodale, M.A. (2006). Object Representations Share the Same Neural Substrate? In: M.A. Heller, S. Ballesteros (eds.). Touch and Blindness. Psychology and Neuroscience (pp. 139-155). Mahwah: Lawrence Erlbaum Associates.

Jay, M. (1993). Downcast Eyes. The Denigration of Vision in Twentieth-Century French Thought. Berkeley - Los Angeles - London: University of California Press.

Jenks, Ch. (ed.) (1995). Visual Culture. London - New York: Routledge.

Landau B., Gleitman L.R. (1985), Language and experience: evidence from the blind child, Cambridge: Harvard University Press.

Kinash, S. (2006). Seeing Beyond Blindness. Greenwich: Information Age Publishing.

Kleege, G. (1999). Sight Unseen. New Haven - London: Yale University Press.

Kleege, G. (2005). Blindness and Visual Culture: An Eyewitness Account. Journal of Visual Culture, 4 (2), 179-190.

Kleege, G. (2010). Blind Faith. The Yale Review, 98 (3), 57-67.

Konecki K.T. (2000). Studia z metodologii badań jakościowych. Teoria ugruntowana. Warszawa: PWN. 
Koster-Hale J., Bedny M., Saxe R. (2014), Thinking about seeing: Perceptual sources of knowledge are encoded in the theory of mind brain regions of sighted and blind adults. Cognition, 133, 65-78.

Kurz, I., Kwiatkowska, P., Zaremba, Ł. (eds.) (2012). Antropologia kultury wizualnej. Warszawa: Wydawnictwa Uniwersytetu Warszawskiego.

Lassiter L.E. (2005). The Chicago Guide to Collaborative Ethnography. Chicago - London: The University of Chicago Press.

Lowenfeld, B. (1975). The Changing Status of the Blind. From Separation to Integration. Springfield: Charles C. Thomas Publisher.

Magee, B., Milligan, M. (1995). On Blindness. Oxford: Oxford University Press.

Magnusson, A.-K., Karlsson, G. (2008). The Body Language of Adults Who Are Blind. Scandinavian Journal of Disability Research, 10 (2), 71-89.

Michalko, R. (1998). The Mystery of the Eye and the Shadow of Blindness. Toronto: University of Toronto Press.

Michalko, R. (2002). The Difference that Disability Makes. Philadelphia: Temple University Press.

Mirzoeff, N. (1999). An Introduction to Visual Culture. London - New York: Routledge.

Mirzoeff, N. (2015). How to See the World. London: Penguin Books.

Mitchell, W.J.T. (2005). What Do Pictures Want? The Lives and Loves of Images. Chicago London: The University of Chicago Press.

Monbeck, M.E. (1975). The Meaning of Blindness. Attitudes Toward Blindness and Blind People. Bloomington - London: Indiana University Press.

Pallasmaa, J. (2009). The Thinking Hand: Existential and Embodied Wisdom in Architecture. Chichester: Wiley.

Pallasmaa, J. (2012), The Eyes of the Skin: Architecture and the Senses. Chichester: Wiley.

Paterson, M. (2006). Seeing with the Hands, Touching with the Eyes: Vision, Touch and the Enlightenment Spatial Imaginary. The Senses and Society, 1 (2), 225-243.

Paterson, M. (2007). The Senses of Touch. Haptics, Affects and Technologies. Oxford - New York: Berg.

Pietrowiak, K. (2019) (in print). Świat po omacku. Etnograficzne studium (nie)widzenia i (nie) sprawności. Torun: Wydawnictwo UMK.

Rampley, M. (ed.) (2005). Exploring visual culture: definitions, concepts, contexts. Edinburgh: Edinburgh University Press.

Robins, K. (1996). Into the Image. Culture and politics in the field of vision. London - New York: Routledge.

Sacks, O. (1996). The Mind's Eye. New York: Alfred A. Knopf.

Saerberg, S. (2010). "Just Go Straight Ahead". How Blind and Sighted Pedestrians Negotiate Space. Senses \& Society, 5 (3), 364-381.

Scott, R.A. (1969). The Making of Blind Man: A Study of Adult Socialization. New York: Russell Sage Foundation.

Sendyka R. (2011). Antropologia zmysłów. Autoportret, 35, 20-27.

Smith, M. (2008). Visual Culture Studies. Los Angeles - London - New Delhi - Singapore: Sage.

Titchkosky, T. (2003). Disability, Self, and Society, Toronto - Buffalo - London: University of Toronto Press.

Vaughan C.E. (1998), Social and Cultural Perspectives on Blindness. Barriers to Community Integration. Springfield: Charles C Thomas Publisher.

Walthes, R. (2007). Tyflopedagogika. Transl. by J. Mink. Gdańsk: Gdańskie Wydawnictwo Psychologiczne. 
Warnke, G. (1993). Ocularcentrism and Social Criticism. In: D.M. Levin (ed.), Modernity and the Hegemony of Vision (pp. 287-308). Berkeley: University of California Press.

Wells, H. G. (1998). The country of the blind. London: Travelman.

Whearley, E. (2010). Stumbling Blocks Before the Blind. Medieval Constructions of a Disability. Ann Arbor: The University of Michigan Press.

Wyka A. (1993), Badacz społeczny wobec doświadczenia. Warszawa: Wydawnictwo IFiS PAN.

Zaremba, Ł. (2016). \#zobaczyć świat. Od tłumacza. In: N. Mirzoeff, Jak zobaczyć świat (pp. 5-15). Transl. by Ł. Zaremba. Kraków-Warszawa: Karakter.

\section{SUMMARY}

The aim of this article is to present the way congenitally blind individuals understand and imagine the functioning of sight and its general value. The Author discusses the category of visual culture, values and meanings attributed to visual cognition, as well as selected theories on blindness that significantly affect the worldview of the research participants. The empirical base of this presentation is ethnographic research on the practices and strategies of blind individuals, conducted in 2011-2017.

Keywords: blindness, visual culture, senses, disability, collaborative ethnography 